\title{
Car-safety lobby on collision course with researchers
}

Tony Reichhardt, Washington

After years of fighting off interference from radio transmitters and broadcast satellites, astronomers are worried that an emerging technology - collision-avoidance radar for cars - could pose the biggest threat yet to some of their observations.

The astronomers' concerns are this time shared by Earth scientists, who say that the radars could mess up their observation of the atmosphere from satellites. But they face an uphill battle in confronting the commercial interests that support the car radars - not to mention the universally popular goal of increased road safety.

So far, only a handful of luxury cars, including models produced by Cadillac, Mercedes-Benz and BMW, offer onboard radar systems that alert drivers when other cars come too close. But their use is expected to widen in the next decade, and US and European regulators are already planning to allocate a share of the radio spectrum to it.

A ruling by the US Federal Communications Commission (FCC) last year allowed the use of car radars at a frequency of 24 gigahertz $(\mathrm{GHz})$. But both NASA and the National Oceanic and Atmospheric Administration opposed that frequency allocation on the grounds that it could interfere with scientific observations.

For radio astronomers, the $24-\mathrm{GHz}$ band is an important frequency for detecting ammonia - a common extraterrestrial molecule. Studies show that millions of car radars operating at that frequency would "absolutely guarantee to close down the whole band" for astronomy, says Wim van Driel, a radio astronomer at the Paris Observatory.

For climate researchers, the frequency sits squarely in a band that serves as a signature of water vapour in the atmosphere.

John Zuzek, who works on spectrum management issues at NASA's Glenn Research Center in Ohio, says that although other agencies were consulted about the FCC rule, studies showing interference problems with scientific observations were essentially ignored. Zuzek and other researchers say that the FCC is under strong pressure from industry to approve the commercial allocations. "We were kind of forced to go along with what happened, but with a lot of reservations," he says.

Eventually, car radar systems operating at higher frequencies - around $77 \mathrm{GHz}$ are expected to emerge, but these are currently more expensive to make. European regulators are therefore recommending a phased approach, first using the $24-\mathrm{GHz}$ systems, then phasing in the $77-\mathrm{GHz}$

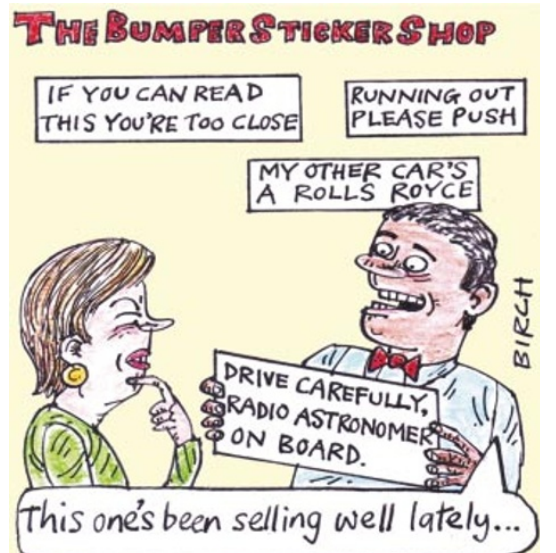

systems as the devices become more common in vehicles.

Shifting to the higher frequencies would suit astronomers - although echoes of $77-\mathrm{GHz}$ signals could still be picked up by sensitive radio dishes listening at the 226-231.5-GHz band, one of the 'windows' in the atmosphere that is transparent to radio observers on the ground.

Several other issues of concern to researchers will be on the agenda at the World Radiocommunication Conference (WRC-03), a giant round of international talks on dividing up the radio spectrum, which kicks off in Geneva this week. Among the most pressing items are allocations in the $5-\mathrm{GHz}$ range for wireless computer networks. If these proliferate, they could interfere with satellite-based imaging radars used for Earth observation.

Historically, astronomers have been fairly successful at winning protection from encroachment by commercial radio services. And scientists took heart last November when an FCC spectrum task force reaffirmed that "radio astronomy may need to have dedicated, protected spectrum bands for the foreseeable future, due to its highly sensitive applications and the fact that its benefits accrue to society as a whole".

Yet the combination of scarce spectrum, new uses of the air waves, and the antiregulatory slant of the current FCC makes this ever more difficult. Astronomers like their mobile phones and wireless Internet connections as much as anyone else, says van Driel, who chairs the European Science Foundation's Committee on Radio Astronomy Frequencies. And he admits that appearing to oppose a technology that could improve road safety "makes us look bad". But in the scramble for spectrum, he insists, "we have the right to be protected".
Pollution fears put work at neutrino laboratory on hold

\section{Nicola Nosengo}

Italy's nuclear physics research authorities have temporarily shut down an underground laboratory in a bid to resolve environmental questions that surround its work.

Almost all research at the Gran Sasso National Laboratory, an underground neutrino lab in central Italy, was halted by the Italian National Institute for Research in Nuclear and Subnuclear Physics (INFN) on 29 May.

The move follows warnings from local officials that toxic chemicals used in the lab could pollute local water supplies. Enzo Iarocci, the INFN president, says the closure is intended to draw attention to the problem, which he believes the national government must solve.

The lab has attracted protests since experiments began a decade ago. Environmental groups argue that the toxic chemicals used in the neutrino detectors could leak into aquifers below the lab. Their protests gathered pace last August, when around 50 litres of trimethylbenzene, a chemical that is toxic in high doses, were spilt during work on the Borexino experiment, which studies low-energy solar neutrinos.

The chemical entered the lab's drainage system, and local environmental officials subsequently detected it in a nearby river, although it was not found in drinking water. The local public prosecutor opened an inquiry into safety procedures at the lab, and the regional government set up a parallel expert inquiry staffed by water engineers, public-health officials and INFN representatives.

After assessing contamination risks, the prosecutor ruled on 29 May that the Borexino experiment area should be sealed up. Iarocci, having been told earlier that week by the expert group that the lab's drainage system could be leaking, the same day suspended all experiments involving liquid materials.

Iarocci says the repairs needed are the national government's responsibility. "The INFN is also trying to give a sign of cooperation to local communities," adds Carlo Gustavino, a Gran Sasso physicist.

Alessandro Bettini, the lab's director, says the national government has reacted positively to the INFN's action, and that work at the lab could restart in around four months, as the repairs needed to the drainage system are minor.

www.Ings.infn.it 